\title{
Sami Coll: \\ The social dynamics of secrecy: Rethinking information and privacy through Georg Simmel
}

\begin{abstract}
:
This article argues that Georg Simmel's ideas on secrecy can shed new light on current debates around the relevance or otherwise of privacy as a protection against surveillance interventions. It suggests an interactional approach to privacy, and considers it as a dynamic process which redefines the boundary between what information should be disclosed and what information should be concealed in every social interaction. Simmel argues that this "natural" process relies on the identification of the interlocutor: her psychological/emotional involvement in the relationship, her social position in society and the representation of her expectations. Recent empirical examples show that this interactional perspective may have the potential to reconcile differing privacy accounts, by linking theoretically different levels that are factually distinct: privacy as a collective fact, as a contextual integrity, and as an individual fact.
\end{abstract}

\section{Agenda:}

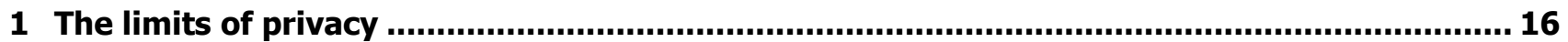

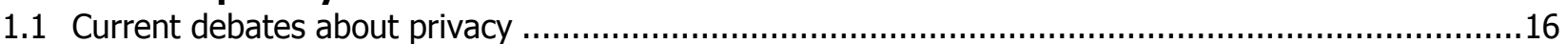

1.2 An empirical perspective: The loyalty card programmes......................................................16

2 Privacy as a social interaction: Simmel's work on secrecy ................................................ 17

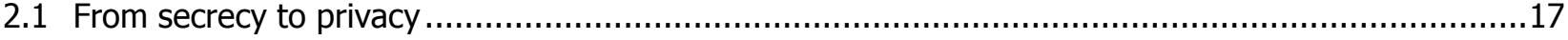

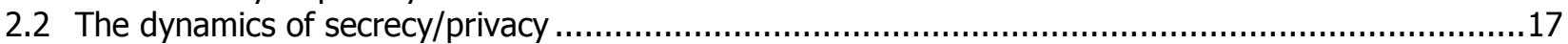

2.3 The spontaneous regulation of the flow of information ....................................................... 18

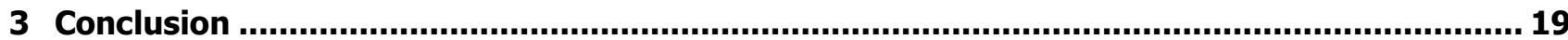

\section{Author:}

Dr. Sami Coll:

- Department of Sociology, University of Geneva, Switzerland

- $\triangle$ socio@samicoll.com, 邑 www.samicoll.com 
In 1906, German Sociologist Georg Simmel published a pioneering paper on secrecy in the American Journal of Sociology: 'The Sociology of Secrecy and of Secret Societies'. It was later revised and published in 1908 in his mother tongue as a chapter of Soziologie: Untersuchungen über die Formen der Vergesellschaftung, then retranslated to English and published in 1950 as The Secret and the Secret Society. At the beginning of the $20^{\text {th }}$ century, the notion of privacy was not developed to the extent it is now, especially with respect to the emergence of the information society (Regan 2011, 497). However, the social dynamics of secrecy analysed in Simmel's writings appear to be similar to those that can be observed in the context of the information era. Indeed, Simmel suggests an "exploration of the role of information in social interactions" (Marx and Muschert 2009, 217). Focusing exclusively on the social dimensions of informational practice, Simmel avoids being drawn into an ethical position on how and/or whether information flows should be regulated. As such, Simmel's analysis does not reduce the richness of social reality to a duality between an emitter and a receptor, as it tends to be in data protection policies. For these reasons, I argue in this paper that Simmel's theory on secrecy is able to shed an intriguing light upon privacy and data protection debates.

\section{The limits of privacy}

\subsection{Current debates about privacy}

While most scholars agree that the privacy notion is vague and not rigorous enough to address issues relating to contemporary surveillance practices (Bennett 2008), disagreements emerge around how rights to a private life should be protected in cultures defined by ubiquitous surveillance. Traditional approaches still advocate for approaching privacy from the level of the individual (Bennett 2008; Bennett 2011a), arguing that there is a legislative regime already in place which can be exploited to provide citizenry protection (Bennett 2011b; Stalder 2011). Other scholars argue that the concept should be withdrawn and replaced with alternative values (like Gilliom 2011). I have previously described how privacy might be understood as a close ally of surveillance (Coll 2010). This is because the notion tends to be exploited by privileged groups to perpetuate forms of capital accumulation, much like the artistic critique was absorbed in the late $20^{\text {th }}$ century by regimes concerned to maintain the political-economic status quo (Boltanski and Chiapello 2005). Certain scholars argue that in order to be more effective, privacy should be approached with a relational and/or contextual perspective (Nissenbaum 2009; Steeves 2009), whilst others contend that it should be transformed to become a more collective project (Regan 1995; Regan 2011; Gilliom 2011). Despite the indisputable importance of these approaches, the distinction between the relational/contextual perspective and the collective perspective is not always very evident.

\subsection{An empirical perspective: The loyalty card programmes}

My recent empirical research on people's attitudes to loyalty card programs attempts to move beyond often abstract theoretical discussions on the capacity of privacy legislation to protect individuals and populations from diverse forms of surveillance (Coll 2010). Results from this research show that there are - in the specific context of loyalty programmes - three different perspectives on privacy to consider. First, what might be understood as official and legal informational privacy. Upheld by various laws generated in the context of the information society, this form of privacy is generally viewed as a fundamental right which protects individuals from undesired intrusions and unlawful interference from the state, private companies, or simply other persons motivated by curiosity (Stalder 2002, 121). Second, consumers' subjective privacy, as consumers themselves define it, relates to a freedom of choice ideology, or the freedom of making decisions without being influenced by a third party. Third, privacy as an everyday life experience relates to the actual situations where actors feel that their privacy is being breached, particularly as a result of loyalty card programmes that collect, conserve and potentially analyse their personal data. My observations in a loyalty card call centre, for example, showed that consumers were more annoyed by the identity verification questions fielded by operators - although there are meant to protect their privacy - than by the company's storage of their personal data. On the contrary, consumers expect companies to retain their data. When consumers 
contacted the same call centre to ask for a hardcopy of a lost warranty, they were not pleased to discover that in order to protect their privacy the database did not contain details of their recent purchases.

An important question emerges at this point: how is it possible to generate an approach to privacy as a form of protection against the effects of massive data collection and processing if there is no agreement among legislators or individuals on its constitutive form? As shown, consumers themselves display much ambivalence towards privacy. Most of the time, their verbalized definitions do not correspond with how they endure privacy breaches in everyday life. My research showed that the informational self-determination principle guiding data protection laws - i.e. that every person is supposed to be a proactive guarantor of her own privacy (using freedom of access legislation to correct or erase inaccurate information), is seriously challenged by the scale of contemporary surveillance operations and individuals' general lack of knowledge on how, why and from where data is collected.

\section{Privacy as a social interaction: Simmel's work on secrecy}

\subsection{From secrecy to privacy}

Simmel's work on secrecy - and using it to frame an approach of privacy as an interactional and social property - offers a novel perspective from which we might move beyond existing contradictions and paradoxes.

First, Simmel reminds us that a society with "full publicity" (Simmel 1950a, 330) would not be stable and would rupture the interaction order, a similar position to that adopted by Solove: "A society without privacy protection would be suffocating, and it might not be a place in which most would want to live" (Solove 2007, 762). Simmel then contends that "one can never know another person absolutely, which would involve knowledge of every single thought and mood. Nevertheless, one forms some personal unity out of those of his fragments in which alone he is accessible to us. This unity, therefore, depends upon the portion of him which our standpoint permits us to see" (Simmel 1950a, 308). Indeed, the information sought by a person on another can come from "many sources of information (...) and many carriers" (Goffman 1959, 1).

Finally, Simmel speaks of secrecy as "the feeling (...) that an ideal sphere lies around every human being. Although differing in size in various directions and differing according to the person with whom one entertains relations, this sphere cannot be penetrated, unless the personality value of the individual is thereby destroyed" (Simmel 1950a, 321). In other words, there is no doubt that the "ideal sphere" described by Simmel is precisely what is now commonly known as the sacrosanct realm of "privacy".

It is in Simmel's thick description reported above where overlaps between his secrecy reflections and privacy debates become evident, specifically because the "ideal sphere" cannot be seen as a static "bubble" which would supposedly contain private or sensitive data. The "ideal sphere" instead emerges from dynamic social interactions and the boundary between private and public is continuously in flux.

\subsection{The dynamics of secrecy/privacy}

Much like communication, secrecy, as a social dynamic, guarantees a society's social cohesion. Any social relation requires a balance between disclosure and concealment, and this balance needs to be negotiated in each social interaction: "the secret is a form which constantly receives and releases contents: what originally was manifest becomes secret, and what once was hidden later sheds its concealment" (Simmel 1950a, 335). Information which might be perceived as private in one context can be disclosed in another where it is not considered such. For example, a customer in a bakery would most probably not feel transgressed by someone wishing to know her favourite bread variety, but she might experience discontent or discomfort if asked the size of her panties. In contrast, in a clothes shop, providing information on size is mandatory to the provision of a good service, while being asked about favourite bread type might be deemed inappropriate, 
and potentially induces a feeling of privacy invasion. Thus, the context of the social interaction defines the relevance of the informational disclosure as well as its (in)appropriateness.

While this theoretical model is well suited in the context of a face-to-face interaction, it becomes more complex when it involves an interaction between an individual and an institution, whether public or private. The image of the institution can be mixed-up with the person representing the institution during an interaction. The definition of the boundary between what information should be transmitted (considered public in this context) and what information should be concealed (private) will, naturally, depend on what service the person expects of the institution, but also on the personality and projected judgements of the employee in charge of providing the service. In my research, feelings that privacy had been breached were expressed in very concrete situations. They involved the personal characteristics of an employee rather than the ones of the organization. For example, when a young man at customer services asks a middle-aged woman for her date of birth, the woman feel discomfort by the fact the employee is younger, and not because the company can possibly use her date of birth for marketing purposes. Indeed, interactions remain in large part interactions between two human beings even in the contextual parameters of an organisation: "Every relationship between persons gives rise to a picture of each in the other; and this picture, obviously, interacts with the actual relation" (Simmel 1950a, 309). This image is partly based on the organizational setting but in large part emerges as an outcome of the quality of interaction shared between interlocutor and individual.

\subsection{The spontaneous regulation of the flow of information}

Simmel considers the dynamic process of agreeing and upholding the boundary between private and public information as a "natural" process (Simmel 1950a, 311-312). The term "natural" is probably inappropriate as this process is in fact historically and normatively contingent. It is integrated through the socialisation of individuals into particular codes of conduct (DePaulo et al. 2003). The decision to disclose or conceal information is made spontaneously and subconsciously (this is actually what Georg Simmel meant by the "natural" or organic framing of this dynamic). On the one hand, we can reasonably assume that the social and spontaneous nature of this process permits mutually regulated flow of information in the context of everyday life and face-to-face relationships. On the other hand, when it comes to regulating the flow of personal information through digitalized devices, this spontaneous ability may no longer be available as a checking device.

This dynamic process becomes more complex when the interlocutor is virtual and thus more difficult to clearly discern. Indeed, the "natural" regulation of informational flow as described by Simmel is based on the fact that the interlocutor is clearly identifiable. For example, consider the case of completing a website application form: the identification of the interlocutor and one's capacity to build an appropriate image of it cannot be made as in a face-to-face interaction. In this case, a set of important social rules and conventions are absent. In contrast, consider the situation of completing a form at a customer service desk. Here, it is the employee and not the organization that is clearly identifiable. The boundary tends to be delimited according to the identification and the evaluation of the employee's conduct rather than that of the company more generally.

In the case of social network sites like Facebook, it is not easy to clearly identify the interlocutor neither. Is it a group of "friends", a "friend" of a "friend" or a future "friend" who will have access to previously published data? Will it be anyone registered on the network? In such a context, evaluating the receptor of a message (a picture, a status, a video, etc.) is extremely complex, if not impossible. Thus, the "natural" process mentioned by Simmel is not able to conceal the risks of an inappropriate disclosure of sensitive information. However, no substitute for spontaneous regulation is currently available. Therefore, this regulation principle continues to govern the disclosure of data in the current information age, and this approach has several limitations in terms of ensuring an order that is mutually constituted. 


\section{Conclusion}

An interactional approach to privacy, based on Simmel's theory of secrecy, enables us to understand paradoxical situations. On the one hand, measures meant to protect an individual's privacy are the very mechanisms which produce a feeling of invasion. On the other hand, such reactions do not occur in situations where they are expected. It also reminds us that the relationship between an individual and an institution is often mediated by an employee who proves decisive in deciding the boundary between what to conceal and what to disclose.

Several important issues need to be borne in mind. First, the notion of secrecy (that is to say, privacy) always implies an "Other" (Marx and Muschert 2009, 223). An "ontological" privacy can only exist in relation to an interlocutor. Second, secrecy dynamics are relational and context-dependent. The definition of the context involves many parameters: the identification of the interlocutor, her role in the institution, her psychological/emotional involvement in the relationship, her social position in the society, her expectation (or, rather, our projected view of her expectations), etc.

According to Simmel, interactions are at the origin of social structures of power (Simmel 1950b; Coser 1977). The social dynamics of secrecy are not an exception. Rather than being a social fact in which we should protect an individual's privacy and liberty, information (and its partner, secrecy) is thus constitutive of the individual and her social relations. In other words, when a certain boundary between disclosure and concealment is repeated through certain types of social relations, it becomes a structure, and then a collective fact. As the capacity to withhold specific information becomes a commodity constitutive of power and social stratification (Simmel 1950a, 338), secrecy (which is, again, in Simmel's language, privacy) has an important collective implication, one which is defended by those scholars wishing to retain privacy as a collective good (see Westin 2003; Regan 1995; Regan 2011).

Adopting Simmel's theory on social interactions and on secrecy enables an interesting approach to be built around the sociology of intimacy and privacy. Such an approach may have the potential to reconcile existing privacy debates, and link different privacy forms that are factually distinct: privacy as a collective fact, as a contextual integrity and as an individual fact. It can, for example, lead us to a better understanding of the social dynamics and the modalities of transparency operating in and across social networks (Coll, Glassey, and Balleys 2012).

\section{References}

Bennett, Colin J. 2008. The Privacy Advocates: Resisting the Spread of Surveillance. Cambridge, MA: MIT Press.

- 2011a. "In Defence of Privacy: The Concept and the Regime." Surveillance \& Society 8 (4): 485-496.

—. 2011b. "In Further Defence of Privacy..." Surveillance \& Society 8 (4): 513-516.

Boltanski, Luc, and Eve Chiapello. 2005. The New Spirit of Capitalism. London, New York: Verso Books.

Coll, Sami. 2010. "Consommation Sous Surveillance: L'exemple Des Cartes De Fidélité". PhD diss. Genève: Université de Genève, Faculté des sciences économiques et sociales.

Coll, Sami, Olivier Glassey, and Claire Balleys. 2012. "Building Social Networks Ethics Beyond 'privacy': a Sociological Perspective. "International Review of Informational Ethics 16.

Coser, Lewis. 1977. Masters of Sociological Thought: Ideas in Historical and Social Context. New York: Harcourt Brace Jovanovich.

DePaulo, Bella M., Chris Wetzel, R. Weylin Sternglanz, and Molly J. Walker Wilson. 2003. "Verbal and Nonverbal Dynamics of Privacy, Secrecy, and Deceit." Journal of Social Issues 59 (2): 391-410.

Gilliom, John. 2011. "A Response to Bennett's 'In Defence of Privacy'." Surveillance \& Society 8 (4): 500504.

Goffman, E. 1959. The Presentation of Self in Everyday Life. New York: Anchor Books, Doubleday. 
Marx, Gary T., and Glenn W. Muschert. 2009. "A Legacy and Inheritance for the Sociology of Information." In Soziologie Als Möglichkeit: 100 Jahre Georg Simmels Untersuchungen Über Die Formen Der Vergesellschaftung, ed. Cécile Rol and Christian Papilloud, 217-233. Wiesbaden, Germany: VS Verlag für Sozialwissenschaften.

Nissenbaum, Helen. 2009. Privacy in Context: Technology, Policy, and the Integrity of Social Life. Standford: Stanford University Press.

Regan, Priscilla M. 1995. Legislating Privacy. Chapel Hill \& London: The University of North Carolina Press.

—. 2011. "Response to Bennett: Also in Defence of Privacy." Surveillance \& Society 8 (4): 497-499.

Simmel, Georg. 1950a. "The Secret and the Secret Society." In The Sociology of Georg Simmel,ed. Kurt H. Wolff, trans. Kurt H. Wolff, 305-376. Glencoe IIl.: Free Press.

1950b. The Sociology of Georg Simmel. Ed. Kurt H. Wolff. Trans. Kurt H. Wolff. Glencoe IIl.: Free Press.

Solove, Daniel J. 2007. "'I've Got Nothing to Hide' and Other Misunderstandings of Privacy. "San Diego Law Review 44: 745-772.

Stalder, Felix. 2002. "Opinion. Privacy Is Not the Antidote to Surveillance." Surveillance \& Society 1 (1): 120124.

2011. "Autonomy Beyond Privacy? A Rejoinder to Bennett." Surveillance \& Society 8 (4): 508-512.

Steeves, Valerie. 2009. "Reclaiming the Social Value of Privacy." In Lessons from the Identity Trail: Anonymity, Privacy and Identity in a Networked Society, ed. Ian Kerr, Carole Lucock, and Valerie Steeves, 193208. New York: Oxford University Press.

Westin, Alan F. 2003. "Social and Political Dimensions of Privacy." Journal of Social Issues 59 (2): 431-453. 